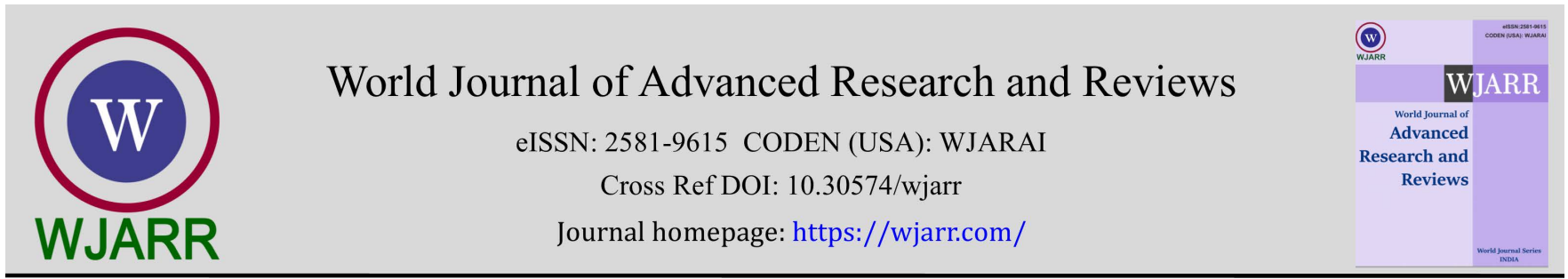

(RESEARCH ARTicle)

\title{
Pollination efficiency of Apis mellifera (Hymenoptera: Apidae) on Cosmos sulphureus (Asteraceae) capitula at Dang (Ngaoundéré, Cameroon)
}

\author{
Boris Kevin Maben Biroki * and Fernand-Nestor Fohouo Tchuenguem \\ Laboratory of Zoology, Department of Biological Sciences, Faculty of Science, University of Ngaoundere, P.O. Box 454 \\ Ngaoundere, Cameroon.
}

World Journal of Advanced Research and Reviews, 2021, 09(01), 175-187

Publication history: Received on 27 November 2020; revised on 02 January 2021; accepted on 03 January 2021

Article DOI: https://doi.org/10.30574/wjarr.2021.9.1.0452

\begin{abstract}
To study the foraging activity of Apis mellifera (Hymenoptera: Apidae) on Cosmos sulphureus (Asteraceae) and to evaluate its impact on fruits yields, $C$. sulphureus capitula were observed on Dang (Ngaoundéré, Cameroon) from September to November 2016 and from August to October 2017. Each year, observations were made every day, from 06.00 am to $6.00 \mathrm{pm}$ on 540 capitula divided in four treatments: 120 capitula left in free polliniation, 120 capitula protected from insects ; 200 capitula protected, then uncovered, exclusively visited by A. mellifera and rebagged ; 100 capitula protected, then uncovered and rebagged without insect or any other organism visit. The foraging behaviour on A. mellifera capitula, its pollination efficiency, the fruiting rate, the percentage of mature achenes and the percentage of normal (well developed) achenes were evaluated. The results show that among 10 insect species recorded on $C$. sulphureus capitula after two seasons of observation, A. mellifera was the most represented with $95.57 \%$ of 1128 visits. This bee harvested intensely nectar and pollen on $C$. sulphureus florets. The fruiting rate, the percentage of mature akenes and the percentage of normal achenes of treatments with unprotected capitula were significantly higher than those of treatments with capitula protected from insects. Through the pollination efficiency of a single capitule visit, $A$. mellifera increased the fruiting rate, the percentage of mature achenes and the percentage of normal achenes by 50.58 $\%, 14.37 \%$ and $40.52 \%$ respectively. The installation of $A$. mellifera colonies close to $C$. sulphureus fields is recommended to increase achenes and honey yields, as well as pollen production as a hive product.
\end{abstract}

Keywords: Apis mellifera; Cosmos sulphureus; Capitula; Pollination efficiency; yields.

\section{Introduction}

In ecosystems, the reproduction of many flowering plants needs pollination; this action can be done through agents such as wind, water and animals among which insect are found [1]. The pollination of a great number of plants species mainly depends on insects of the Order Hymenoptera [2]. In many regions of the world, the activity of pollinating insects is judiciously exploited, because it is well known [3]. In Tropical Africa, the impact of pollination on the fruits yields of plants and the contribution of plants to the feeding of pollinating insects is slightly known [4].

Apis mellifera is a social insect, native from Europe,Near and Middle East and Africa [5]. It is the most important bee especially for its honey, wax and propolis production [6]. During their foraging trips, the workers of this bee can harvest nectar, pollen or the two products used as food and achieve at the same time an excellent work of pollination [1].

\footnotetext{
${ }^{*}$ Corresponding author: Biroki Maben Boris Kevin

Laboratory of Zoology, Department of Biological Sciences, Faculty of Science, University of Ngaoundere, P.0. Box 454 Ngaoundere, Cameroon.
}

Copyright (c) 2021 Author(s) retain the copyright of this article. This article is published under the terms of the Creative Commons Attribution Liscense 4.0. 
Cosmos sulphureus is an herbaceous of the family Asteraceae, native from America [Bindurani, 2013]. It is used in the textile industry for making dyes; in pharmaceutic, it presents anti-malaria, anti-inflammatory and anti-bacterial properties; it is also used in gardening [7].

The productivity of $A$. mellifera colonies depends mainly on the attractiveness and the abundance of polleniferous and nectariferous plants in the environment of the apiaries [8]. The apicultural value of a plant species represents its potential in ressources exploitable by bees like pollen, nectar and honeydew [3].

The number of investigations carried out in Cameroun on the relations between plants and insects is increasing [e.g. 3 , 9]. In spite of the preliminary studies of Tchuenguem et al. [9] in Cameroon and Wróblewska et al. in Poland [10] showing that $A$. mellifera visits $C$. sulphureus, there are no published data to our knowledge on the pollination efficiency of $A$. mellifera on $C$. sulphureus. In this same country, the demand for seeds of $C$. sulphureus, honey and pollen is high, while their production is low [11].

This work carried out in Ngaoundéré, had as main objective to contribute to the mastery of the relations that exist between $C$. sulphureus and $A$. mellifera, for their optimum management. The specific objectives were: determination of the place of $A$. mellifera into the floral entomofauna of $C$. sulphureus ; study of the activity of $A$. mellifera on the capitula of this plant species ; estimation of the apicultural value of the Asteraceae; evaluation of the impact of the flowering insects on the pollination and akenes yields of $C$. sulphureus; estimation of the pollination efficiency of $A$. mellifera on this plant species.

\section{Material and methods}

\subsection{Material}

\subsubsection{Study site and biological material}

Experiments were carried out from May to November 2016 and from May to October 2017 at Dang (Latitude 7०25.365 N, Longitude $13^{\circ} 32.572 \mathrm{E}$ and Altitude 1083.), a village in the town of Ngaoundéré, in the Adamawa Region of Cameroon [12]. This Region covers $62000 \mathrm{~km}^{2}$ and belongs to the high-altitude Guinean-savanna agro-ecological zone. This climate is characterized by two seasons: a rainy season (April to October) and a dry season (November to March) [3]. The annual rainfall is about $1500 \mathrm{~mm}$ [13]. The mean annual temperature varies from $22.08^{\circ} \mathrm{C}$ to $22.93^{\circ} \mathrm{C}$ and the mean annual relative humidity varies from $64.1 \%$ to $67.6 \%$ [12]. The vegetation is a savannah and gallery forests in some places [3].

The plant material was made up of achenes of $C$. sulphureus grown in the study site. The animal material included: a) 52 to 72 A. mellifera colonies numbered from September 2016 to August 2017; b) unidentified colonies of this bee, since they can attain a radius of $12 \mathrm{~km}$ around the hive in search of food [14]; c) many other insects naturally present in the environment of the study site.

\subsection{Methods}

\subsubsection{Determination of the reproduction mode of Cosmos sulphureus}

In September 2016 and August 2017, from the emergence of the first capitule with florets at bud stage, 240 of them have been labelled each year, and divided into two treatments:

Treatment 1 (2016) or 3 (2017): 120 capitula labelled and left unprotected to allow insects visits and on which no insect capture was made;

Treatment 2 (2016) or 4 (2017): 120 capitula labelled and bagged to avoid insects' visits using gauze bags [15].

For each study year, at the harvest, the number of formed achenes was assessed in each treatment. The fruiting index was then calculated as described by Tchuenguem et al. [15]: $P i=F 2 / F 1$, where $F 2$ the number of formed achenes and F1 the number of viable florets initially set.

The allogamy rate (TC) from which is deduced the autogamy rate $(T A)$ was calculated as the difference of fruiting indexes between treatment $X$ (unprotected florets) and treatment $Y$ (protected florets) [3]. 
$T C=[(P i X-P i Y) / P i X] * 100$, where $P i X$ and $P i Y$ are respectively the mean fruiting indices in treatment $X$ and treatment $Y$.

$T A=100-T C$

\subsubsection{Determination of the place of Apis mellifera in the floral entomofauna of Cosmos sulphureus}

To determine the place of $A$. mellifera in the floral entomofauna of $C$. sulphureus, observations was made on treatments 1 and 3 every day, from the opening of the first capitule bud (12 $2^{\text {th }}$ of September 2016 and of $21^{\text {st }}$ August 2017). Data were taken from $06.00 \mathrm{am}$ to $6.00 \mathrm{pm}$ according to six daily time frames: 6 - $7 \mathrm{am}, 8-9 \mathrm{am}, 10-11 \mathrm{am}, 12 \mathrm{am}-1 \mathrm{pm}, 2$ - $3 \mathrm{pm}$ and $4-5 \mathrm{pm}$. For each of these time slots, the different insects encountered on blooming florets of $C$. sulphureus were counted [3]. Cumulative results were expressed as the number of visits [15]. Data on the frequency of visits of the various identified flowering insects have made it possible to determine the place of $A$. mellifera in the anthophilous entomofauna of $C$. sulphureus. The frequency of visits of the insect $i$ on $C$. sulphureus florets (Fi) was calculated using the following formula: $F i=\{[(V i) / V I] * 100\}$, with $V i$ the number of insect $i$ visits on unprotected capitula, and $V I$ the number of visits of all recorded insect on the same capitula [3].

Specimens of all insect taxa, excluded A. mellifera were captured on unlabelled capitula using an insect net and kept in $70 \%$ ethanol, excluding butterflies that were kept dry [16], for later taxonomic identification.

\subsubsection{Study of Apis mellifera activity on Cosmos sulphureus florets}

Observations of the foraging activity of A. mellifera on the florets of $C$. sulphureus were made according to six daily time frames: 7 - $8 \mathrm{am}, 9-10 \mathrm{am}, 11-12 \mathrm{am}, 1-2 \mathrm{pm}, 3-4 \mathrm{pm}$ and $5-6 \mathrm{pm}$. On each sampling day, the number of opened florets was counted. The floral product harvested (nectar or pollen) by worker bees during each floral visit was registered; nectar gatherers were seen extending their proboscis into the base of the corolla, while pollen harvesters directly scratched anthers with their mandibles and legs [13]. We also determined the abundance of foragers (highest number of individuals foraging simultaneously on a floret, a capitule or 1000 florets) and the foraging speed (number of florets visited by A. mellifera per minute). Abundances per floret and per capitule were recorded following the direct counting, on the same dates and daily periods as for the registration of the duration of visits. For the abundance per 1000 florets $\left(A_{1000}\right)$, some foragers were counted on a known number of florets; $A_{1000}$ was then calculated using the formula $A_{1000}=\left((A x / F x)^{*} 1000\right)$, with $F x$ and $A x$ are the number of opened florets and the number of foragers effectively counted on these florets at time $x$ [15]. The foraging speed was recorded. It corresponds to the number of flowers visited per minute [3]. The zeroed stopwatch was started as soon as a worker landed on a floret and stopped as soon as this bee was lost to follow-up or if it left the visited capitulum for another plant species. Concomitantly, the number of florets visited was counted. The foraging speed $(F s)$ was calculated using the formula $F s=(F l / d u)^{*} 60$, where $d u$ is the duration (sec) given by a stopwatch, and $F l$, the number of visited florets during $d u$ [3]. This parameter was recorded on the same dates and daily periods as for the registration of the duration of visits, at the rate of at least five values per time frame when the activity of the foragers allowed it [3]. Moreover, the number of pollinating visits (a bee comes into contact with the stigma) [3] were assessed on the same dates and time frames as for the registration of the duration of visits.

The interruptions of the activity of foragers by competitors or predators and the attractiveness of other plant species flowers with respect to A. mellifera were evaluated. During each observation day, ambient temperature and relative humidity were registered after every 30 minutes from 6 am to $6 \mathrm{pm}$, using a mobile thermo-hygrometer installed in the shade [3].

\subsubsection{Evaluation of the apicultural value of Cosmos sulphureus}

The apicultural value of $C$. sulphureus was assessed as in other plant species [11], using data on flowering intensity and the attractiveness of $A$. mellifera workers with respect to nectar and pollen. The concentration in total sugars of $C$. sulphureus florets nectar was recorded using a portable refractometer (0 - $90 \%$ Brix) and a thermometer giving the ambient temperature [17]. Apis mellifera workers in full activity of nectar harvest were captured on the capitula and anesthetized by their introduction into a small bottle containing cotton moistened with chloroform, since the nectar of C. sulphureus is not directly accessible to the investigator [11]. Then, by small pressures on the bee abdomen placed between the thumb and the forefinger of the experimenter, the nectar was expelled from the crop and its concentration in total sugars (in dry matter $\mathrm{g} / 100 \mathrm{~g}$ ) measured [17].

The recorded values were corrected according to the ambient temperature. Data were recorded in 2016 and 2017, during the same daily periods as for the registration of the abundance of foragers. Five values were registered for each daily time frame according to the bee's rhythm of activity [17]. 


\subsubsection{Evaluation of the impact of flowering insects including Apis mellifera on Cosmos sulphureus yields}

In parallel to the implementation of treatments 1 to 4, 600 capitula with florets at bud stage were labelled to set four other treatments:

Treatments 5 (2016) or 7 (2017): 200 capitula protected, destined to be uncovered, visited once by A. mellifera then rebagged. As soon as the florets on each capitula of treatment 5 or 7 bloomed, the gauze bag was gently removed and the florets left in free pollination, observed for 1 to 10 minutes to note their possible visit by A. mellifera. After this manipulation, the capitula were reprotected and no longer handled. The unvisited capitula were included in treatments 6 or 8 [9].

Treatments 6 or 8 (2017): 100 capitula protected, then uncovered and reprotected without insects or any other organism visits. As soon as the florets on each capitula of treatments 6 or 8 bloomed, the gauze bag was delicately removed and the blooming florets observed for 1 to 10 minutes, while preventing insects or any other organism visits. After this manipulation, the capitula were rebagged and no longer handled 8 [9].

At the maturity of achenes in treatments 5, 6, 7 and 8, they were harvested, their quality appreciated and their number determined.

The evaluation of the impact of anthophilous insects including A. mellifera on achenes production of $C$. sulphureus was based on the impact of anthophilous insects on pollination, the impact of pollination on the fruiting of $C$. sulphureus and the comparison of achenes production (fruiting rate, percentage of mature achenes and percentage of normal or welldeveloped achenes) of treatments 1, 2, 3, 4, 6 and 8 [3]. For each year of investigation, the fruiting rate due to flowering insects (Fri) is calculated using the following formula:

$F r i=\{[(F X-F Z) /(F X+F Y-F Z)] * 100\}$, where $F X, F Y$ and $F Z$ are the fruiting rates in treatments $X$ (capitula left in free pollination), $Y$ (capitula protected from insects) and $Z$ (capitula protected, uncovered then rebagged, without insects or any other organism visits), respectively [13].

For each treatment, the fruiting rate $(F)$ is:

$F=$ (number of formed achenes / number of viable florets initially borne) $* 100$ [13].

The percentage of mature achenes and the percentage of normal achenes due to flowering insects were calculated according to the same method as for the fruiting rate.

\subsubsection{Assessment of the pollination efficiency of Apis mellifera on Cosmos sulphureus}

The contributions of A. mellifera in the fruiting rate, the percentage of mature achenes and the percentage of normal achenes were calculated using data from treatments 5, 6, 7 and 8 .

For each observation period, the fruiting rate due to A. mellifera (Fam) was calculated using the following formula:

$F a m=\{[(F A-F Z) / F A] * 100[13]$, Where $F A$ is the fruiting rate in treatment 5 or 7 (capitula protected, then uncovered, visited exclusively by $A$. mellifera and reprotected) and $F Z$ the fruiting rate in treatment 6 or 8 (bagged capitula, opened and closed without insects or any other organism visit).

The contributions of $A$. mellifera in the percentage of mature achenes and the percentage of normal achenes were calculated in the same way as for the fruiting rate.

\subsubsection{Data analysis}

Data were subjected to descriptive statistics (means, standard deviations and percentages), ANOVA $(F)$ for the global comparison of more than two means, Student's $t$-test for the comparison of two means, Pearson correlation coefficient $(r)$ for the study of the linear relationships between two variables and Chi-square $\left(\chi^{2}\right)$ for the comparison of percentages. Microsoft Excel 2010 software was used for this purpose. 


\section{Results and discussion}

\subsection{Reproduction mode of Cosmos sulphureus}

The fruiting indices were $0.53,0.19,0.42$ and 0.17 in treatments $1,2,3$ and 4 respectively. Thus, in 2016, TC was 64.15 $\%$ and $T A$ was $35.85 \%$; in 2017 TC was $59.53 \%$ and $T A$ was $40.47 \%$. For the two cumulated years; TC was $61.84 \%$ and $T A$ was $38.16 \%$. Consequently, $C$. sulphureus has a mixed reproduction mode (allogamy and autogamy) with the predominance of allogamy over autogamy.

\subsection{Concentration in total sugars of Cosmos sulphureus nectar}

The mean concentration in total sugars of $C$. sulphureus nectar was $32.90 \%(n=35 ; s=2.14 ;$ minimum $=25.25 \%$; maximum $=33.81 \%)$ in 2016 and $31.81 \%(n=37 ; s=3.35 ;$ minimum $=25.39 \%$; maximum $=33.91 \%)$ in 2017 . The difference between these two means is significant $(t=1.99 ; d f=68 ; P<0.05)$. For the two years, the mean concentration in total sugars of $C$. sulphureus was $32.36 \%(n=72 ; s=2.75)$.

\subsection{Place of Apis mellifera in the floral entomofauna of Cosmos sulphureus}

Among the 601 and 527 visits of 9 and 5 insect species recorded on C. sulphureus flowers in 2016 and 2017 respectively, A. mellifera was the most represented insect species in each study year, with 563 visits (93.68 \%) and 515 visits (97.72 $\%)$, in 2016 and 2017 respectively (Table 1). The difference between these two percentages is highly significant $(\chi 2=$ 10.85; $d f=1 ; P<0.001)$. Similar results were obtained by Wróblewska et al. [9] in Poland, presenting $A$. mellifera as the most frequent floral insect of $C$. sulphureus with $51.7 \%$ of visit. Honeybees are known to be among the most frequent floral insects present on other plant species such as Bidens bipinnata and Bidens pilosa [18] ; Achillea millefolium, Brachyscome multifida, Senecio icoglossus, Tithonia diversifolia, Trichocline catharinensis and Zinnia elegans [6] ; Ceratotheca sesamoides [9] ; Helianthus annuus [11]. The significant difference between the frequencies of visits of this bee and those of other insects can be explained by the strategies adopted by this bee, which consists in recruiting a great number of workers for the exploitation of an interesting food source [19]. This invasion may then cause a limitation of the number of visits of other insect species,that find the open florets almost completely occupied by $A$. mellifera.

Table 1 List of flowering insects on Cosmos sulphureus in September 2016 and August 2017, number and percentage of visits of different insects.

\begin{tabular}{|c|c|c|c|c|c|c|c|c|}
\hline \multicolumn{3}{|l|}{ Insects } & \multicolumn{2}{|c|}{2016} & \multicolumn{2}{|c|}{2017} & \multicolumn{2}{|l|}{ Total } \\
\hline Order & Family & Genus and species & $n_{1}$ & $p_{1}(\%)$ & $n_{2}$ & $p_{2}(\%)$ & $n_{T}$ & $p_{T}(\%)$ \\
\hline \multirow[t]{2}{*}{ Diptera } & Bombylidae & (sp. 1) (ne) & 5 & 0.83 & 0 & 0 & 5 & 0.44 \\
\hline & & (sp. 2) (ne) & 1 & 0.17 & 0 & 0 & 1 & 0.09 \\
\hline \multirow[t]{4}{*}{ Hymenoptera } & Apidae & Apis mellifera (ne, po) & 563 & 93.68 & 515 & 97.72 & 1078 & 95.57 \\
\hline & & Braunsapis sp. (po) & 2 & 0.33 & 3 & 0.57 & 5 & 0.44 \\
\hline & & Xylocopa olivacea (ne) & 1 & 0.17 & 0 & 0.00 & 1 & 0.09 \\
\hline & Halictidae & Halictus sp (ne) & 0 & 0.00 & 2 & 0.38 & 2 & 0.17 \\
\hline \multirow[t]{4}{*}{ Lepidoptera } & Nymphalidae & Acraea sp. (ne) & 10 & 1.66 & 1 & 0.19 & 11 & 0.97 \\
\hline & & Hypolimnas misippus (ne) & 14 & 2.33 & 6 & 1.14 & 20 & 1.77 \\
\hline & & Precis sp. 1 (ne) & 2 & 0.33 & 0 & 0.00 & 2 & 0.17 \\
\hline & Geometridae & (sp. 1) (ne) & 3 & 0.50 & 0 & 0.00 & 3 & 0.27 \\
\hline \multicolumn{2}{|l|}{ Total } & 10 species & 601 & 100 & 527 & 100 & 1128 & 100 \\
\hline
\end{tabular}

$n_{1}$ : number of visits on 120 capitula in six days ; $n_{2}$ : number of visits on 120 capitula in seven days ; $n_{T}=$ total number of visits on 240 capitula in 13 days ; $p_{1}$ and $p_{2}$ : percentages of visits $; p_{1}=\left(n_{1} / 601\right) * 100 ; p_{2}=\left(n_{2} / 527\right) * 100 ; p_{T}=$ total percentage of visits; sp.: unidentified species ; ne : nectar harvest ; po : pollen harvest

Comparison of percentages of Apis mellifera visits for the two study years: $\chi^{2}=10.85(d f=1 ; P<0.001)$. 


\subsection{Activity of Apis mellifera on Cosmos sulphureus capitula}

\subsubsection{Products harvested}

During each flowering season, $A$. mellifera regularly and intensively gathered nectar. It regularly and less intensively harvested pollen. While harvesting nectar (Figure 1), this bee collected pollen in a passive way, in addition to the active collection of pollen (Figure 2).

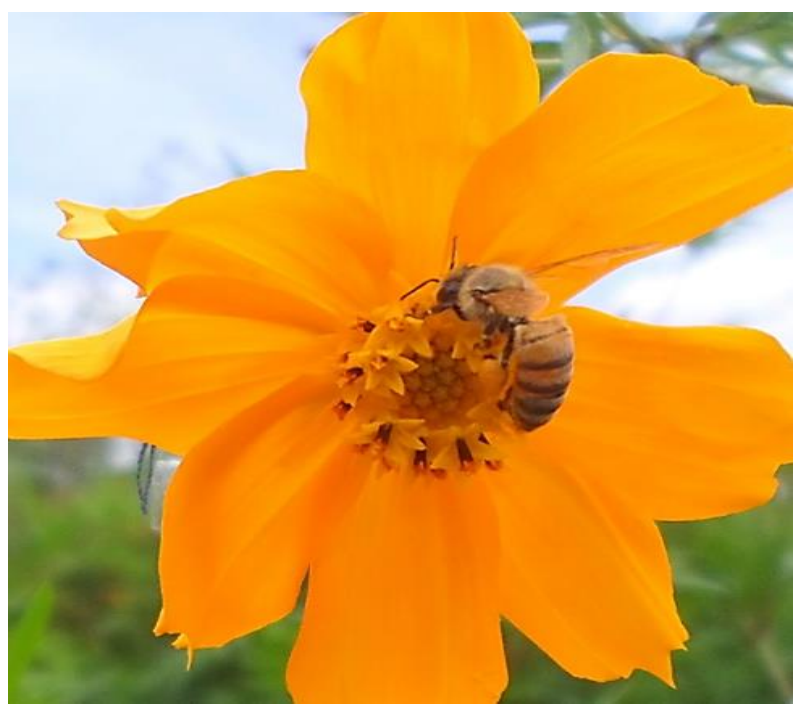

Figure 1 Apis mellifera harvesting nectar in a floret of Cosmos sulphureus at Dang in 2017.

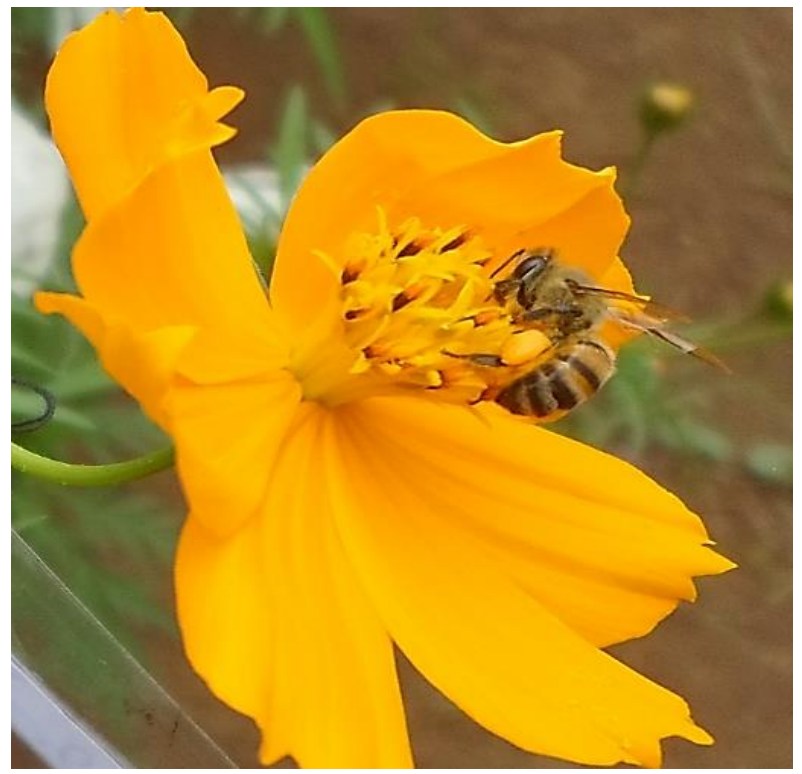

Figure 2 Apis mellifera harvesting pollen on florets of Cosmos sulphureus at Dang in 2017

\subsubsection{Rhythm of visits of according to the blooming of florets}

Visits increased with the opening increase of capitula and florets of $C$. sulphureus (Figure 3). Moreover, we found a positive and significant correlation between the number of opened florets and the number of visits in 2016 ( $\mathrm{r}=0.94$; $\mathrm{df}$ $=4 ; \mathrm{P}<0.05$ ) and a positive and a highly significant correlation between the number of opened capitula and the number of visits in 2017 ( $\mathrm{r}=0.92 ; \mathrm{df}=5 ; \mathrm{P}<0.001$ ). These positive and significant correlations between the number of $C$. sulphureus opened florets and the number of visit of $A$. mellifera underscores the attractiveness of $C$. sulphureus nectar and/or pollen for A. mellifera. A positive and significant correlation between this bee and the blooming progression of florets was also obtained by Egono et al. [11] on H. annuus. 


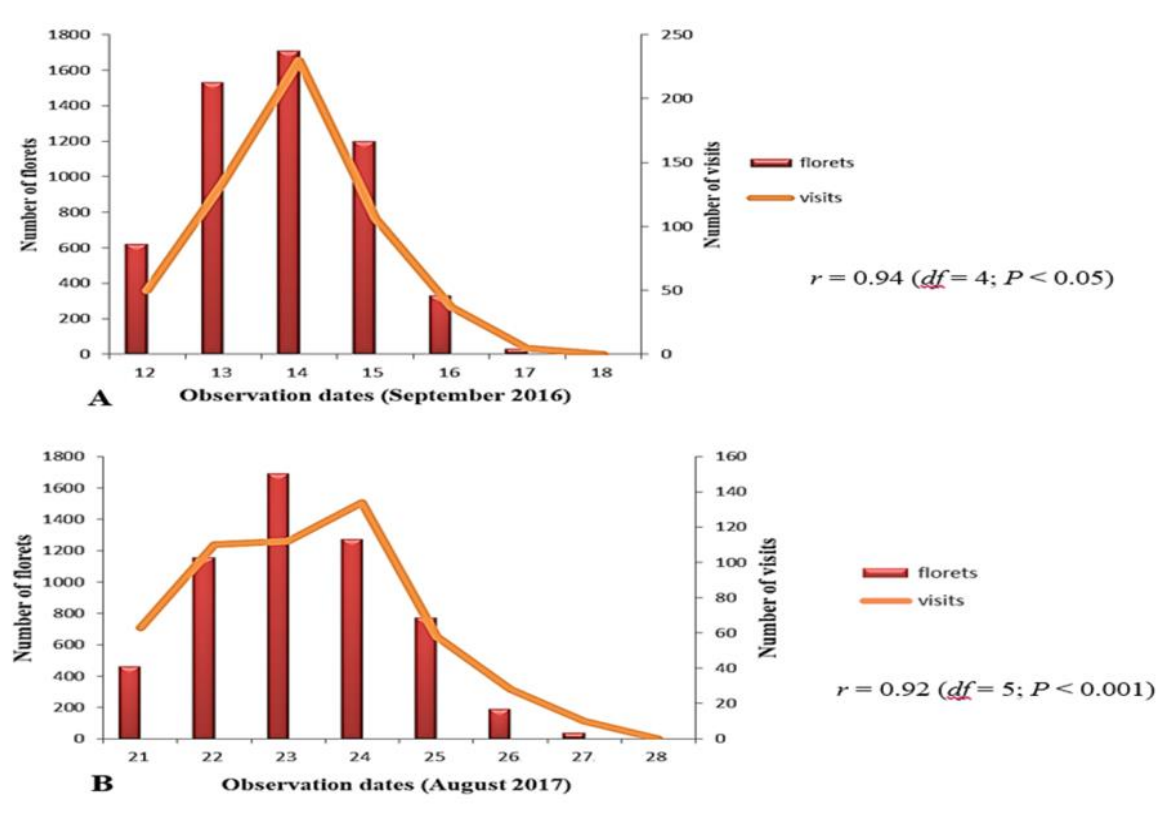

Figure 3 Variations of the number of Cosmos sulphureus opened capitula and the number of Apis mellifera visits on these organs according to the observation dates in 2016 (A) and 2017 (B) at Dang.

$\mathrm{r}$ : correlation coefficient between the number of florets and the number of visits ; $\mathrm{df}$ : degree of freedom ; P : probability

\subsubsection{Rythm of Apis mellifera visits according to the daily time frames}

Apis mellifera started its foraging activity on C. sulphureus flowers at around 6 am and ended at about 6 pm, with a peak of visits situated between 8 am and 9 am in 2016 as well as in 2017 (Figure 4). The peak of activity of $A$. mellifera observed on $C$. sulphureus capitula could be linked to the fact that these time frame may be the period of highest secretion of nectar, greatest availability of pollen on anthers, and secretion of a large quantity of volatile substances attracting bees [1]. This result is not in accordance with those of Wróblewska et al., [1] that found a peak of foraging insects including $A$. mellifera between $12 \mathrm{pm}$ and $4 \mathrm{pm}$. This difference may be due to the fact that insect activity vary over time and space [3].

\subsubsection{Abundance of Apis mellifera foragers}

In 2016, the highest mean number of $A$. mellifera simultaneously in activity was 2 per floret $(n=1626 ; s=0.06)$, 53 per 1000 florets $(n=415 ; s=28.28)$ and 151 per 1000 capitula $(n=776 ; s=97.78)$. In 2017, the corresponding values were 2 per floret $(n=1274 ; s=0.07)$, 35 per 1000 florets $(n=537 ; s=19.27)$ and 222 per 1000 capitula $(n=598 ; s=119.81)$. For the two study periods, the greatest mean number of $A$. mellifera workers simultaneously in activity was 1 per floret, 44 per 1000 florets and 187 per 1000 capitula. The difference between the highest mean numbers of $A$. mellifera simultaneously in activity per 1000 florets $(t=11.65 ; d f=949 ; P<0.001)$ in 2016 and 2017 was highly significant. The difference between the highest mean numbers of $A$. mellifera simultaneously in activity per 1000 capitula $(t=12.08 ; d f$ $=1372 ; P<0.001$ ) in 2016 and 2017 was highly significant. The observed high abundance of workers on $C$. sulphureus capitula was due to the ability of honeybees to recruit a great number of foragers for the exploitation of profitable food sources [1].

\subsubsection{Duration of visits}

In 2016, the mean duration of one visit of $A$. mellifera was $12.64 \mathrm{sec}$ per capitulum $(n=623 ; s=7.95)$ for nectar harvest and $9.47 \mathrm{sec}$ per capitulum $(n=169 ; \mathrm{s}=4.29)$ for pollen collection; the mean duration of visit was $1.79 \mathrm{sec}$ per floret $(n$ $=977 ; s=0.88$ ) for nectar harvest and $1.52 \mathrm{sec}$ per floret $(n=195 ; s=0.75)$ for pollen collection. In 2017, the mean duration of a visit was $12.81 \mathrm{sec}$ per capitulum $(n=554 ; s=8.67)$ for nectar gathering and 10.09 sec per capitulum $(n=$ $110 ; s=5.58)$ for pollen collection; the mean duration of one visit of $A$. mellifera was $1.80 \sec$ per floret $(n=821 ; s=$ $0.80)$ for nectar harvest and $1.39 \mathrm{sec}$ per floret $(n=180 ; s=0.60)$ for pollen harvest.

For the two study periods, the difference between the mean durations of a visit of $A$. mellifera per capitulum for nectar collection is not significant $(t=0.35 ; d f=1175 ; P>0.05)$; the difference between the mean durations of a visit per capitule for pollen collection is not significant $(t=1.04 ; d f=277 ; P>0.05)$; the difference between the duration of visit 
of $A$. mellifera per floret for nectar collection is not significant $(t=0.25 ; d f=1796 ; P>0.05)$; the difference between the duration of one visit of $A$. mellifera per floret for pollen collection is not significant $(t=1.84 ; d f=373 ; P>0.05)$.

For the two cumulative years, the mean duration of a visit for nectar harvest was $12.73 \mathrm{sec}$ and $1.78 \mathrm{sec}$ per capitule and per floret respectively. For pollen collection, it was $9.78 \mathrm{sec}$ and $1.46 \mathrm{sec}$ per capitule and per floret respectively. The variation between the mean durations of visit for nectar and pollen harvest could be linked to the accessibility and availability of these floral products. The $C$. sulphureus pollen which is produced by anthers is easily accessible to $A$. mellifera whereas nectar is produced between the base of the style and stamens and is thus less accessible. Under these conditions, a forager was obliged to spend more time on a floret to harvest nectar, compared to the needed time for pollen collection; similar observations were made on $H$. annuus in Ngaoundéré [20].

\subsubsection{Foraging speed}

On C. sulphureus plots, A. mellifera visited between 7 and 200 florets per min in 2016 and between 9 and 150 florets per $\min$ in 2017. The mean foraging speed was 51.39 florets per $\min (n=657 ; s=32.01)$ in $2016,56.87$ florets per min $(n$ $=702 ; s=23.81$ ) in 2017 and 54.13 florets per min for the two cumulated years. The difference between the first two means per floret is highly significant $(t=3.59 ; d f=1357 ; P<0.001)$. The observed variations in the foraging speed may be due to the distance between the capitula during the various foraging trips and the frequency of interruption of $A$. mellifera visits. In Ngaoundéré, on Helianthus annuus with bigger florets, $A$. mellifera visited an average of 24.37 florets per minute [21], a more than twice lower foraging speed compared to what we obtained. This difference may be due to the variation of the activity of this bee over time and with plant species as mentioned by Tchuenguem et al. [22].

\subsubsection{Influence of fauna}

Apis mellifera workers were interrupted in their foraging activity on $C$. sulphureus by other individuals of the same or different species. These individuals were either predators or competitors for nectar or pollen. Disruptions occurred after collisions between visitors or by approaching a capitulum already occupied by another worker. In 2016 , for 1182 visits of $A$. mellifera, 58 (4.90\%) were interrupted, whereas in 2017, for 1015 visits of this bee, 49 (4.83\%) were interrupted (Table 2). Visits' interruptions reduced the duration of certain honeybees' visits. This obliged some workers to visit more capitula during a foraging trip, in order to obtain their maximal pollen or nectar loads. Similar findings were made for A. mellifera workers foraging on the flowers of Persea americana (Lauraceae) and Vitellaria paradoxa (Sapotaceae) in Ngaoundere [22].

Table 2 Interrupted visits of Apis mellifera on Cosmos sulphureus capitula in 2016 and 2017 at Dang

\begin{tabular}{|c|c|c|c|c|}
\hline \multirow[t]{2}{*}{ Years } & \multirow{2}{*}{ Number of studied visits } & \multicolumn{2}{|c|}{ Visits interrupted by insects } & \multirow{2}{*}{$\begin{array}{l}\text { Insect responsible of } \\
\text { visits' interruption }\end{array}$} \\
\hline & & Number & Percentage (\%) & \\
\hline \multirow[t]{3}{*}{2016} & \multirow[t]{3}{*}{1182} & 56 & 4.74 & Apis mellifera \\
\hline & & 1 & 0.08 & Acraea sp. \\
\hline & & 1 & 0.08 & Hypolimnas misippus \\
\hline \multirow[t]{3}{*}{2017} & \multirow[t]{3}{*}{1015} & 47 & 4.63 & Apis mellifera \\
\hline & & 1 & 0.10 & Acraea sp. \\
\hline & & 1 & 0.10 & Halictus sp. \\
\hline
\end{tabular}

\subsubsection{Influence of neighbouring flora}

During the observations periods, flowers of many other plant species situated close to C. sulphureus plots were visited by A. mellifera workers for nectar (ne) or pollen (po). Among these plants were Bidens pilosa (Asteraceae ; ne and po), Bixa orellana (Bixaceae ; ne and po), Cajanus cajan (Fabaceae; ne), Emilia coccinea (Asteraceae ; ne and po), Helianthus annuus (Asteraceae; ne and po), Lantana camara (Verbenaceae ; ne), Mimosa invisa (Mivosaceae ; po), Sida rhombifolia (Malvaceae ; ne and po), Tithonia diversifolia (Asteraceae; ne and po) and Vigna subterranea (Fabaceae ; ne). During their foraging trips, $A$. mellifera foragers left $C$. sulphureus capitula for Bidens pilosa only twice, in 2016 . This result indicates a flower constancy of $A$. mellifera on $C$. sulphureus. This floral constancy is due to the fact that, individual forager of honeybees is generally able to memorize and recognize the shape, the colour and the odour of the visited flowers during previous foraging trips [1] ; it may also be due to the good organization of honeybees, recruiting a large 
number of workers for an efficient exploitation of an interesting food source [23] and to the good level of floral reward in nectar and pollen to the foragers [24] .

\subsubsection{Influence of climatic factors}

During the investigation periods, the temperature and the relative humidity of the air did not significantly influence the activity of $A$. mellifera on $C$. sulphureus. In 2016, there was no correlation between the number of $A$. mellifera visits and the temperature $(r=0.13 ; d f=4 ; P>0.05)$ as well as between the number of visits and relative humidity $(r=-0.09 ; d f$ $=4 ; P>0.05$ ) (Figure 4, A). In 2017, there was no correlation between the number of $A$. mellifera visits and the temperature $(r=0.35 ; d f=4 ; P>0.05)$; as well as between the number of visits and relative humidity $(r=-0.34 ; d f$ $=4 ; P>0.05$ ) (Figure 4, B).

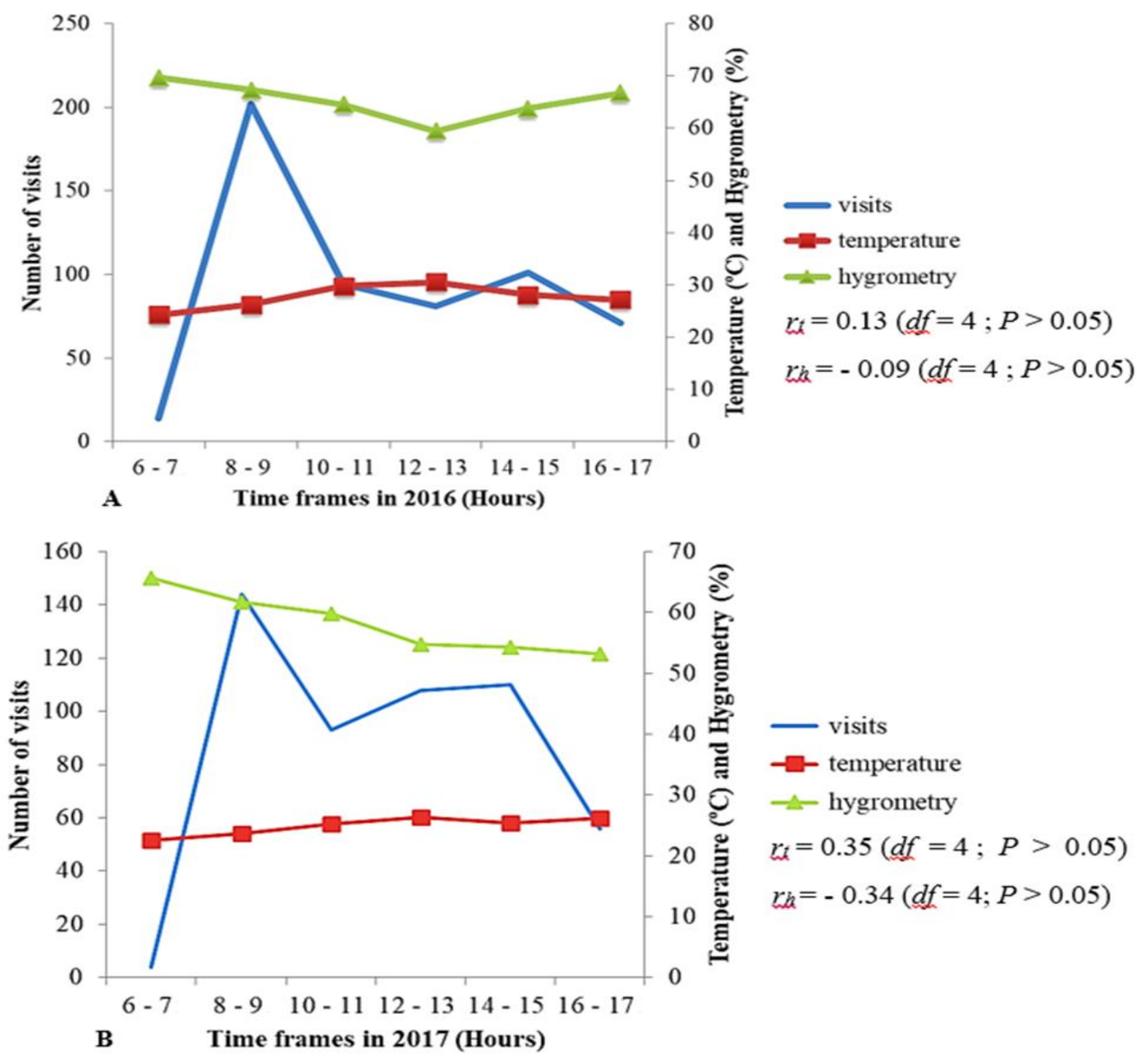

Figure 4 Daily variation of Apis mellifera visits on Cosmos sulphureus florets, mean temperature and mean relative humidity of the study site in 2016 (A) and in 2017 (B).

$r_{t}$ : correlation coefficient between the number of visits and temperature; $r_{h}$ : correlation coefficient between the number of visits and hygrometry ; $d f$ : degree of freedom ; $P$ : probability

\subsection{Apicultural value of Cosmos sulphureus}

During the flowering periods of $C$. sulphureus, a well elaborated activity of $A$. mellifera workers was observed on its capitula. There was a good daily and seasonal frequency of visits, a high density of workers per capitula, a very good nectar and pollen harvest and a fidelity of workers to the capitula. Moreover, each $C$. sulphureus plant can produce over 100 capitula $(n=16 ;$ mean $=146.38 ; \min =80 ; \max =230)$. These data highlight the very good attractiveness of $C$. sulphureus nectar and pollen to A. mellifera. Therefore, $C$. sulphureus is a highly nectariferous and polliniferous bee plant. This Asteraceae could be grown to: a) help stabilize $A$. mellifera colonies during the rainy season; b) increase honey yield; c) improve pollen production as a beehive product. 
Other species of Asteraceae have been identified as honey bees polliniferous (po) and nectariferous (ne) plant species : Vernonia amygdalina (ne ; po) and Vernonia cinerea in Nigeria (ne ; po) [25] ; Bidens pilosa (ne ; po), Bidens bipinnata (ne ; po) and Tridax procumbens (ne ; po) in Benin [23] ; Calendula officinalis (po), Centaurea macrocephala (po), Dahlia pinnata (po), Tagetes patula (po), Tithonia rotundifolia (po) and Zinnia elegans (po) in Poland [10]; Helianthus annuus (ne ; po) and Eugenia uniflora (ne ; po) in Cameroon [11, 26].

\subsection{Impact of flowering insects including Apis mellifera on Cosmos sulphureus yields}

While harvesting nectar and pollen on florets, workers got into contact with anthers and then gathered pollen over their body. Apis mellifera workers increased the possibilities of self-pollination and cross-pollination of $C$. sulphureus while moving from one capitulum to another. For the two study years, the frequency of contact between foragers and the stigma was $100 \%$ for nectar harvest as well as for pollen collection.

In Table 3 are presented the fruiting rate, the percentage of mature achenes and the percentage of normal achenes in the different $C$. sulphureus treatments. It appears from this table that:

- the fruiting rates were $53.29 \%, 19.10 \%, 42.42 \%, 16.94 \%, 50.43 \%, 27.17 \%, 35.33 \%$ and $15.65 \%$ in treatments 1 to 8 respectively. The differences between these eight percentages are globally highly significant $\left(\chi^{2}=3938.44 ; d f=7\right.$ ; $P<0.001$ ). Two - to - two comparisons showed that the difference observed is highly significant between treatments 1 and $2\left(\chi^{2}=1209.69 ; d f=1 ; P<0.001\right)$ as well as between treatments 3 and $4\left(\chi^{2}=916.31 ; d f=1 ; P<0.001\right)$. Consequently, in 2016 and 2017, the fruiting rate of uncovered capitula (treatments 1 and 3) was higher than that of capitula bagged during their flowering period (treatments 2 and 4);

- the percentages of mature achenes were $98.99 \%, 85.72 \%, 98.25 \%, 73.73 \%, 97.34 \%, 89.01 \%, 96.31 \%$ and $73.47 \%$ in treatments 1 to 8 respectively. The differences between these eight percentages are globally highly significant $\left(\chi^{2}=\right.$ 1688.64; $d f=7 ; P<0.001$ ). Two - to - two comparisons showed that the difference observed was highly significant between treatments 1 and $2\left(\chi^{2}=298.42 ; d f=1 ; P<0.001\right)$, as well as between treatments 3 and $4\left(\chi^{2}=557.10 ; d f\right.$ $=1 ; P<0.001)$. So, in 2016 and 2017, the percentage of normal achenes from unprotected capitula was higher than that from capitula protected from insects' visits;

- the percentages of normal achenes were $86.55 \%, 49.59 \%, 97.26 \%, 42.78 \%, 82.37 \%, 50.39 \%, 94.73 \%$ and $51.25 \%$ in treatments 1 to 8 respectively. The differences between these eight percentages are globally highly significant $\left(\chi^{2}=\right.$ 2963.75; $d f=7 ; P<0.001$ ). Two - to - two comparisons showed that the difference observed was highly significant between treatments 1 and $2\left(\chi^{2}=477.22 ; d f=1 ; P<0.001\right)$, as well as between treatments 3 and $4\left(\chi^{2}=1337.94\right.$; $d f=1 ; P<0.001$ ). Thus, in 2016 and 2017, the percentage of normal achenes from unprotected capitula was higher than that from capitula protected from insects' visits.

Table 3 Fruiting rate, percentage of mature achenes and percentage of normal achenes according to the different treatments of Cosmos sulphureus in 2016 and 2017 at Dang.

\begin{tabular}{|l|l|l|l|l|l|l|l|l|}
\hline Treatments & Years & NSF & NFA & \% FR & NMA & \% NMA & NNA & \% NA \\
\hline 1 (Uc) & 2016 & 5399 & 2877 & 53.29 & 2848 & 98.99 & 2465 & 86.55 \\
\hline $2(\mathrm{Bc})$ & & 4435 & 847 & 19.10 & 726 & 85.72 & 360 & 49.59 \\
\hline $3(\mathrm{Uc})$ & 2017 & 6212 & 2635 & 42.42 & 2589 & 98.25 & 2518 & 97.26 \\
\hline $4(\mathrm{Bc})$ & & 5710 & 967 & 16.94 & 713 & 73.73 & 305 & 42.78 \\
\hline $5(\mathrm{Cpva})$ & 2016 & 6562 & 3309 & 50.43 & 3221 & 97.34 & 2653 & 82.37 \\
\hline $6(\mathrm{Cpwv})$ & & 3684 & 1001 & 27.17 & 891 & 89.01 & 449 & 50.39 \\
\hline 7 (Cpva) & 2017 & 8752 & 3092 & 35.33 & 2978 & 96.31 & 2821 & 94.73 \\
\hline 8 (Cpwv) & & 5228 & 818 & 15.65 & 601 & 73.47 & 308 & 51.25 \\
\hline
\end{tabular}

Uc: capitula left unprotected to allow insect visits; Bc : capitula bagged to avoid insect visits ; Cpva : capitula protected, then uncovered, visited once by Apis mellifera and reprotected; Cbwv : capitula protected, then uncovered and reprotected without insects or any other organism visits; NSF : number of studied florets ; NFA : number of formed achenes ; FR : fruiting rate ; NMA : number of mature achenes ; NNA : number of normal achenes ; NA : normal achenes 
In 2016, the numeric contributions of the anthophilous insects including A. mellifera in the fruiting rate, the percentage of mature achenes and the percentage of normal achenes of $C$. sulphureus were $59.86 \%, 9.94 \%$ and $41.06 \%$ respectively. In 2017, the corresponding figures were $62.24 \%, 22.43 \%$ and $47.19 \%$ respectively. For the two cumulate years, the numeric contributions of flowering insects were $61.05 \%, 16.19 \%$, and $44.13 \%$ for the fruiting rate, the percentage of mature achenes and the percentage of normal achenes respectively. This significant increase in achenes production in the presence of flowering insects including $A$. mellifera is the consequence of their foraging activity on the pollination of the visited flowers.

\subsection{Pollination efficiency of Apis mellifera on Cosmos sulphureus}

In 2016, the numeric contribution of $A$. mellifera via a single capitulum visit on $C$. sulphureus was $47.26 \%$ for the fruiting rate, $8.89 \%$ for the percentage of mature achenes and $36.54 \%$ for the percentage of normal achenes. In 2017 , the corresponding figures were $53.90 \%, 19.85 \%$ and $44.49 \%$ respectively. For the two cumulated years, the numeric contribution of a single visit of $A$. mellifera on the fruiting rate, the percentage of mature achenes and the percentage of normal achenes were $50.58 \%, 14.37 \%$ and $40.52 \%$ respectively.

The intervention of $A$. mellifera in the pollination of this plant species is clearly expressed since its density per 1000 flowers and its foraging speed were high. The positive contribution of $A$. mellifera on the fruiting rate and the percentage of normal achenes was also found in Ngaoundere, on H. annuus [11,20]. Apis mellifera workers also provided allogamous pollination by carrying pollen with their hair, legs, mouthparts, thorax and abdomen, from floret to floret on the capitula of a same plant or to the ones of other plants of the same species.

The numeric contribution of $A$. mellifera in $C$. sulphureus fruiting rate, mature achenes and normal achenes through its pollination efficiency was significantly higher than that of other insects. This shows that $A$. mellifera is one of the major pollinator insect of $C$. sulphureus. Similar results were reported in Cameroon on H. annuus by Tchuenguem et al. [20] in 2009 and Egono et al. [11] in 2018.

\section{Conclusion}

At Dang, Cosmos sulphureus is a plant species that obtains benefits from pollination by insects among which Apis mellifera is one of the most important. This bee intensely harvests nectar and pollen of the Asteraceae. The comparison of achene yields of capitula protected, then uncovered and reprotected without insects or any other organism visit to those of capitula protected then uncovered, visited once by A. mellifera and reprotected, shows the value of honeybees in the increase of achenes yields and normal achenes. Data on the foraging activity of A. mellifera on C. sulphureus capitula enable the classification of this Asteraceae among the highly nectariferous and polliniferous bee plants. Through the pollination efficiency of a visit on a $C$. sulphureus capitulum, $A$. mellifera induced a significant increment of the fruiting rate by $50.58 \%$, the percentage of mature achenes by $14.37 \%$ and the percentage of normal achenes by $40.52 \%$. Thus, $C$. sulphhureus could be protected and grown in the region to : a) increase honey yield ; b) improve pollen production as a hive product ; c) stabilize $A$. mellifera colonies during the rainy season.

\section{Compliance with ethical standards}

\section{Acknowledgments}

Our thanks go to the University of Ngaoundéré, more precisely to the Laboratory of Zoology for the framework made available to us.

\section{Disclosure of conflict of interest}

The authors report no conflict of interest in this work.

\section{References}

[1] Alleaume C. L'abeille domestique (Apis mellifera), exemple pour l'étude de l'attractivité des plantes cultivées sur les insectes pollinisateurs. Thèse de Doctorat Vétérinaire, Ecole Nationale Vétérinaire d'Alfort, France. $2012 ; 112$.

[2] Pires VC, Silveira FA, Sujii ER, Torezani KRS, Rodrigues WA, Albuquerque FA, Rodrigues SMM, Antonieta NS, Pires CSS. Importance of bee pollination for cotton production in conventional and organic farms in Brazil. Journal of Pollination Ecology. 2014; 13(16): 151-160. 
[3] Tchuenguem FF-N. Activité de butinage et de pollinisation d'Apis mellifera adansonii Latreille (Hymenoptera: Apidae, Apinae) sur les fleurs de trois plantes à Ngaoundéré (Cameroun): Callistemon rigidus (Myrtaceae), Syzygium guineense var. macrocarpum (Myrtaceae) et Voacanga africana (Apocynaceae). Thèse de Doctorat d'Etat, Université de Yaoundé I, Cameroun. 2005; 103.

[4] Azo'o EM, Tchuenguem FF-N, Messi J. Influence of the foraging activity of the entomofauna on okra (Abelmoschus esculentus) seed yield. International Journal of Agriculture \& Biology. 2011; 13(5): 761-765.

[5] Han F, Wallberg A, Matthew TW. From where did the Western honeybee (Apis mellifera) originate ? Ecology and Evolution. 2012; 2(8): 1949-1957.

[6] Waykar B, Baviskar RK, Nikam TB. Diversity of nectariferous and pollineferous bee flora at Anjaneri and Dugarwadi hills of Western Ghats of Nasik district (M.S.). Indian Journal of Entomology and Zoology Studies. 2014; 2(4): 244-249.

[7] Bindurani R, Mahesh M, Kamlesh K. Antimicrobial activity of Cosmos sulphureus flowers around Pune. International Journal of Pharmaceutical Research and Development. 2013; 5(09): 27-31.

[8] Tchuenguem FF-N, Djonwangwé D, Brückner D. Foraging behaviour of the African bee (Apis mellifera adansonii) on Annona senegalensis, Croton macrostachyus, Psorospermum febrifugum and Sysygium guineense var. guineense flowers at Ngaoundéré (Cameroon). Pakistan Journal of Biological Sciences. 2008; 11(5): 719-725.

[9] Tchuenguem FF-N, Djakbe DJ, Ngakou A, Wékére C, Louabe S, Faibawa E. Impact de l'activité de butinage de Apis mellifera Linné (Hymenoptera: Apidae) sur la pollinisation et les rendements de Ceratotheca sesamoides Endl. (Pedaliacece) à Dang (Ngaoundéré, Cameroon). Cameroon Journal of Experimental Biology. 2018; 12(1): 22-31.

[10] Wróblewska A, Stawiarz E, Masierowska M. Evaluation of selected ornamental Asteraceae as a pollen source for urban bees. Journal of Apicultural Sciences. 2016; 60(2): 179-191.

[11] Egono NCC, Kingha TBM, Fameni TS, Dounia, Tchuenguem FF-N. Pollination efficiency of Apis mellifera (Hymenoptera: Apidae) on Helianthus annuus (Asteraceae) flowers at Dang (Ngaoundéré, Cameroon). International Journal of Biosciences. 2018; 13(3): 314-328.

[12] Amougou JA, Abossolo SA, Tchindjang M. Variabilité des précipitations à Koundja et à Ngaoundéré en rapport avec les anomalies de la température de l'océan atlantique. Ivory Coast Review of Science and Technology. 2015; 25: $110-124$.

[13] Diguir BB, Pando JB, Fameni TS, Tchuenguem FF-N. Pollination efficiency of Dactylurina staudingeri (Hymenoptera: Apidae) on Vernonia amygdalina (Asteraceae) florets at Dang (Ngaoundéré, Cameroon). International Journal of Research Studies in Agricultural Sciences. 2020; 6(2): 22-31.

[14] Louveaux J. L'abeille domestique dans ses relations avec les plantes cultivées. In: «Pollinisation et Productions végétales», INRA, Paris, France. 1984; 527-555.

[15] Tchuenguem FF-N, Messi J, Brückner D, Bouba B, Mbofung G, Hentchoya HJ. Foraging and pollination behaviour of the African honey bee (Apis mellifera adansonii) on Callistemon rigidus flowers at Ngaoundéré (Cameroon). Journal of the Cameroon Academy of Sciences. 2004; 4: 133-140.

[16] Borror DJ, White RE. Les insectes de l'Amérique du Nord (au nord du Mexique). Edition Broquet, Etats Unis d'Amérique. 1991; 408.

[17] Tchuenguem FF-N, Djonwangwé D, Messi J, Brückner D. Exploitation des fleurs de Entada africana, Eucalyptus camaldulensis, Psidium guajava et Trichillia emetica par Apis mellifera adansonii à Dang (Ngaoundéré, Cameroun). Cameroon Journal of Experimental Biology. 2007; 3: 50-60.

[18] Yédomonhan H, Tossou MG, Akoègninou A, Demènou BB, Traoré D. Diversité des plantes mellifères de la zone soudano-guinéenne: cas de l'Arrondissement de Manigri (Centre-Ouest du Bénin). International Journal of Biological and Chemical Sciences. 2009; 3(2): 355-366.

[19] Frisch KV. The dance language and orientation of bees. Harvard University Press, USA. 1987; 556.

[20] Tchuenguem FF-N, Djonwangwé D, Messi J, Brückner D. Activité de butinage et de pollinisation d'Apis mellifera adansonii sur les fleurs de Helianthus annuus (Asteraceae) à Ngaoundéré (Cameroun). Cameroon Journal of Experimental Biology. 2009; 5(1): 1-9.

[21] Adamou M. Activités de butinage et de pollinisation de Apis mellifera adansonii sur les fleurs de Bixa orellana (Bixaceae) et Brachiaria brizantha (Poaceae) à Ngaoundéré (Adamaoua, Cameroun). Thèse de Doctorat d'Etat, Université de Ngaoundéré, Cameroun. 2017; 133. 
[22] Tchuenguem FF-N, Djongwangwé D, Pharaon AM, Messi J, Brückner D. Exploitation of Dichrostachys cinerea, Vitellaria paradoxa, Persea americana and Securidaca longepedunculata flowers by Apis mellifera adansonii Latreille (Hymenoptera: Apidae) at Dang (Ngaoundéré, Cameroon). International Journal of Tropical Insect Science. 2008; 28(4): 225-233.

[23] Philippe JM. La pollinisation par les abeilles: pose des colonies dans la culture en floraison en vue d'accroître les rendements des productions végétales. EDISUD, la Calade, Aix-en-Provence, France. 1991; 179.

[24] Grüter C, Ratnieks LW. (2011). Flower constancy in insect pollinators (Ngaoundéré, Cameroon). Communicative and Integrative Biology. 2011; 7(6): 633-636.

[25] Akunne CE, Akpan AU, Ononye BU. A checklist of nectariferous and polleniferous plants of African honeybees (Apis mellifera adansonii L.) in Awka, Nigeria. Journal of Apiculture. 2016; 31(4): 379-387.

[26] Dongock ND, Foko J, Pinta JY, Ngouo LV, Tchoumboue J, Zango P. Inventaire des plantes mellifères de la zone soudano - guinéenne d'altitude de l'Ouest Cameroun. Tropicultura. 2004; 22(3): 139 - 145. 